\title{
A New System for Sodium Flux Growth of Bulk GaN \\ Part I: System Development
}

Paul Von Dollen ${ }^{\mathrm{a}, *}$, Siddha Pimputkara, Mohammed Abo Alreesh ${ }^{\mathrm{a}}$, Hamad Albrithen ${ }^{\mathrm{b}, \mathrm{c}}$, Sami Suihkonen $^{\mathrm{d}}$, Shuji Nakamura ${ }^{\mathrm{a}}$ and James S. Speck ${ }^{\mathrm{a}}$

a Materials Department, University of California, Santa Barbara 93106-5050

${ }^{b}$ King Abdulaziz City for Science and Technology, Riyadh, Riyadh, Saudi Arabia

'Physics and Astronomy Depmartment, KAIN, King Saud University, Riyadh, Riyadh, Saudi Arabia

${ }^{d D e p a r t m e n t ~ o f ~ M i c r o-~ a n d ~ N a n o s c i e n c e s, ~ A a l t o ~ U n i v e r s i t y, ~ E s p o o, ~ F i n l a n d ~}$

${ }^{*}$ Corresponding author.

Email-address: paul_vondollen@engineering.ucsb.edu (P. Von Dollen)

\section{Abstract}

Though several methods exist to produce bulk crystals of gallium nitride (GaN), none have been commercialized on a large scale. The sodium flux method, which involves precipitation of GaN from a sodium-gallium melt supersaturated with nitrogen, offers potentially lower cost production due to relatively mild process conditions while maintaining high crystal quality. We successfully developed a novel apparatus for conducting crystal growth of bulk GaN using the sodium flux method which has advantages with respect to prior reports. A key task was to prevent sodium loss or migration from the growth environment while permitting $\mathrm{N}_{2}$ to access the growing crystal. We accomplished this by implementing a reflux condensing stem along with a reusable capsule containing a hermetic seal. The reflux condensing stem also enabled direct monitoring of the melt temperature, which has not been previously reported for the sodium flux method. Furthermore, we identified and utilized molybdenum and the molybdenum alloy TZM as a material capable of directly containing the corrosive sodium-gallium melt. This allowed implementation of a cruciblefree system, which may improve process control and potentially lower crystal impurity levels. Nucleation and growth of parasitic GaN ("PolyGaN") on non-seed surfaces occurred in early designs. However, the addition of carbon in later designs suppressed PolyGaN formation and allowed growth of single crystal GaN. Growth rates for the (0001) Ga face (+c-plane) were up to $14 \mu \mathrm{m} / \mathrm{hr}$ while X-ray omega rocking $(\omega$-XRC) curve full width half-max values were 731 arcseconds for crystals grown ReSubmit_IWBNS IX System Paper Manuscript_PVD_v27 
using a later system design. Oxygen levels were high, $>10^{19}$ atoms $/ \mathrm{cm}^{3}$, possibly due to reactor cleaning and handling procedures.

Keywords: A1. Na flux method A1. Reactor Design; A2. Growth from high temperature solutions; A2. Sodium flux growth; B1. Nitrides; B1. III-Nitrides; B1. Bulk GaN

\section{Introduction}

Bulk crystals of III-nitrides, especially gallium nitride (GaN) represent a major opportunity to improve optoelectronic devices such as LEDs and lasers. Additionally, the availability of low-cost and high quality bulk GaN substrates will enable next-generation high-voltage, high-frequency power devices.[1] Since GaN cannot not be practicably melted,[2,3] the main bulk crystal growth techniques are vapor-based, such as hydride vapor-phase epitaxy (HVPE),[4] or involve precipitation from a supersaturated solution: ammonothermal[5] and the sodium flux method.

Since the first reports of sodium flux growth of GaN in 1997,[6] many groups have made excellent progress. In particular, the group at Osaka University has demonstrated high growth rates,[7] low extended defect density, high optical transparency and excellent electrical properties for their bulk GaN crystals.[8] Major discoveries by the Osaka University group are the use of carbon additions for suppression of parasitic nucleation of $\mathrm{GaN}[9,10]$ along with the invention of a pointseeding technique for production of large-area single crystals.[11]

The sodium flux method is high temperature solution crystal growth from a melt of sodium and gallium under pressurized $\mathrm{N}_{2}$ gas. The high temperatures and pressure along with the chemical composition of the melt promote appreciable nitrogen solubility. Once the melt is supersaturated with nitrogen, GaN precipitation is possible, either on a seed crystal or available surfaces such as crucible walls. The generally undesirable material produced in the latter case is known as "PolyGaN" due to the many small crystallites simultaneously nucleated. The required $\mathrm{N}_{2}$ pressures are in the range of 3-5 MPa, while typical melt temperatures are between 750 and $900{ }^{\circ} \mathrm{C}$.

Due to the corrosive nature of both sodium[12] and gallium[13] along with the elevated process conditions, reactor design is critical to successful execution of the sodium flux technique. In this report, we describe the iterative design and development of an apparatus for performing crystal growth of bulk GaN using the sodium flux technique. As part of this investigation, we carried out a number of experimental growth runs with various equipment designs (denoted Gen I, Gen II and Gen III). We also conducted a corrosion study to identify viable construction materials for critical components. We include further growth results and details in a separate report.[14]

The overall design goal was to arrive at a robust platform where key parameters such as melt composition, melt height and seed position could be repeatedly controlled. Controlling these elements should then translate into realization of an improved bulk GaN crystal growth process that is capable of delivering high crystal quality and high growth rates at relevant scales. 


\section{Reactor Design and Sodium Vapor Control}

Customized pressure vessels (Parr Instrument Co., Moline, IL) were employed to contain the necessary process pressures. Externally, each pressure vessel was outfitted with two isolation valves, a burst or rupture disk for overpressure protection, and a two-conductor brazed ceramic-metal power lead feedthrough. A large center port accommodated a standard $3 / 4$ inch compression fitting, into which as many as seven individual thermocouples or other instruments could be hermetically mounted. Finally, a thermocouple (TC) was situated within the reactor head itself to provide protection against thermal overshoot.

Because the required temperatures for the sodium flux method $\left(>850^{\circ} \mathrm{C}\right)$ exceeded the maximum allowable working temperature of the pressure vessels $\left(350{ }^{\circ} \mathrm{C}\right)$, we developed an internally-heated system that employs low thermal conductivity alumina ceramics. Internal heating allows the use of low-cost stainless steel for pressure containment, which should correspond to economical scale-up to larger systems. For instance, internally heated pressurized reactors have been developed to produce GaAs at diameters up to 8 inches.[15] The internal diameter of our pressure vessel is 4 inches, which readily accommodates a $\sim 1$ inch melt diameter. A schematic of our (Gen III) reactor configuration is shown in Figure 1.

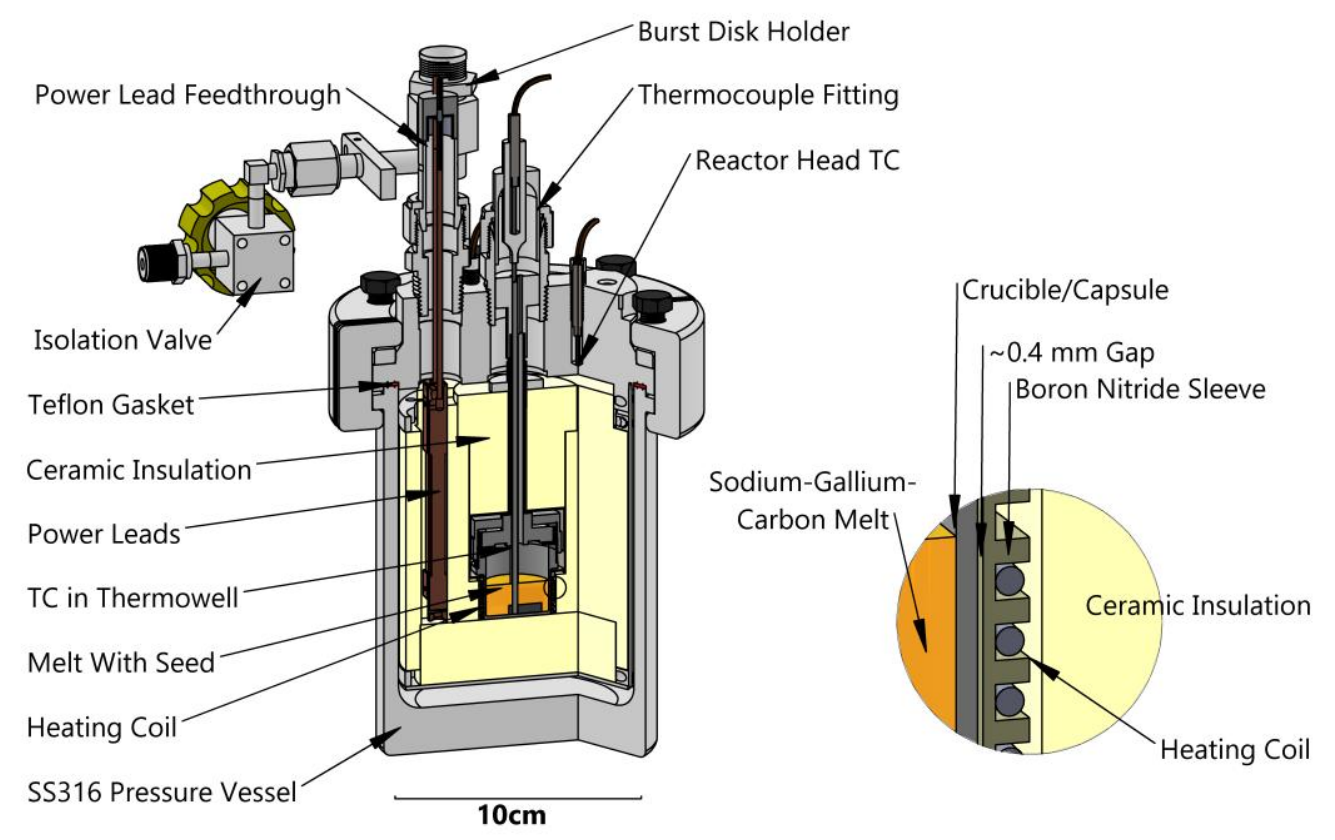

Figure 1. Cutaway view of internally-heated pressure vessel reactor system for sodium flux growth of bulk GaN with Gen III crucible-free capsule shown. Details of earlier designs (Gen I, Gen II) which included alumina crucibles are included below. Inset is heater area detail view.

Collectively, the ceramic insulation pack, heating coil, electrically insulating sleeve and power leads are known as a "hot zone". The resistive heating coil was connected to the electrical power supply through copper power leads within the hot zone and the brazed ceramic-metal feedthrough. 
A thin boron nitride sleeve was located inside the heating coil to provide electrical insulation as well as minimize thermal gradients within the melt.

The sodium-gallium melt within a capsule or crucible was located inside the boron nitride sleeve, with an annular gap of $\sim 0.4 \mathrm{~mm}$ between the two, see inset in Figure 1. For later generation systems, a Type $\mathrm{K}$ thermocouple within a thermowell was used to control the power to the coil and maintain the nominal melt temperature to within $\pm 0.5^{\circ} \mathrm{C}$. Convection to the reactor walls was significant in our system under pressurized growth conditions, with $25-30 \%$ more power required to maintain melt temperatures $>850^{\circ} \mathrm{C}$ at $4.8 \mathrm{MPa}$ as compared to vacuum.

Since a large temperature gradient necessarily exists within the reactor when using internal heating, the colder areas act as a sink for volatile components such as sodium (vapor pressure of 0.1 $\mathrm{MPa}$ at $\sim 883^{\circ} \mathrm{C}$ ). [16] Uncontrolled sodium deposition leads to severe damage to the ceramic hot zone materials. Likewise, the resultant changing melt composition affects the nitrogen solubility[8] as well as melt fluid properties, [17] both of which are critical to the crystal growth process. Given the large molar volume change for nitrogen between gaseous and solid GaN phases, the volumes of $\mathrm{N}_{2}$ gas required for practical crystal growth thicknesses are quite large. So at the same time that sodium vapor must be prevented from exiting the growth environment, $\mathrm{N}_{2}$ gas must be allowed to enter.

\section{Experimental Procedure}

\subsection{Growth Runs}

For all growth runs, selected amounts of pure sodium (99.95\% purity, Alfa Aesar), gallium (99.9999\% purity, Alfa Aesar) and, if used, carbon (natural microcrystal grade APS 2-15 $\mu \mathrm{m}$, 99.9995\% purity, Alfa Aesar) were weighed and placed in either an alumina crucible (Grade AD-998, Coorstek) or directly into the Type 316 stainless steel (SS316), molybdenum or molybdenum TZM alloy $(0.5 \mathrm{wt} \% \mathrm{Ti}, 0.08 \mathrm{wt} \% \mathrm{Zr}, 0.02 \mathrm{wt} \% \mathrm{C}$, balance Mo) capsule. The alumina crucibles were $25 \mathrm{~mm}$ outer diameter (OD) x $22 \mathrm{~mm}$ inner diameter (ID) x $31 \mathrm{~mm}$ tall while metal capsules were $29 \mathrm{~mm}$ OD $x 27 \mathrm{~mm}$ ID x 25 mm tall. Gallium, carbon (if used) and seeds (if used) were loaded into the crucible outside the glove box and prior to addition of sodium. Typical starting gallium concentrations were 20-30 mol\% with carbon at $\sim 0.5 \mathrm{~mol} \%$ with respect to the total melt. Typical total charge volumes were 5-10 mL, or 3-5 g gallium, 5-6 g sodium and $\sim 0.012 \mathrm{~g}$ carbon.

A number of initial runs were conducted without any seeds to ascertain the behavior of the system and refine the process. Two different types of seeds were used for later runs. The first seed type consisted of $\sim 2 \mu \mathrm{m}$ thick $+c$-plane GaN-on-Sapphire templates grown at UCSB using metalorganic chemical vapor deposition (MOVD). The second were $c$-plane bulk GaN seeds cut from boules grown using HVPE (NanoWin, Suzhou, China). Prior to loading, seeds were solvent cleaned followed by air drying. The seeds were placed in a molybdenum seed holder to position them within the melt and to expose more than one crystal face for growth. We conducted growth runs both with and without carbon additions for suppression of PolyGaN nucleation. 
Preparation and loading of sodium and seeds as well as sealing of the capsule and reactor were conducted in an $\mathrm{N}_{2}$ glove box $\left(\mathrm{O}_{2}\right.$ and $\left.\mathrm{H}_{2} \mathrm{O}<1 \mathrm{ppm}\right)$. The oxide layer on the as-received sodium was cut off prior to placement in the crucible/capsule. The sodium was then melted and solidified in the crucible/capsule to prevent any motion or spilling of the metal charge during subsequent reactor handling steps. For early non-capsule runs, the filled crucible was loaded directly into a boron nitride receiver in the hot zone, as shown in Figure 3. For runs employing a capsule, the capsule lower body was sealed to the reflux condenser stem after adding the sodium. The assembled capsule was then placed within the ceramic hot zone and the main reactor was sealed by compressing a Teflon gasket. The thermocouple assembly was inserted into the thermowell, with the control thermocouple within $\sim 2.5 \mathrm{~mm}$ of the bottom of the melt. Finally, the nut for the thermocouple assembly fitting was tightened to seal the entire reactor.

After sealing, the reactor was removed from the glove box and connected to a high-pressure $\mathrm{N}_{2}$ source and the heating coil power supply. The reactor was filled with 2.5-3.5 MPa of high purity $\mathrm{N}_{2}$ (6N, Praxair), isolated from the gas source, and heated to the target temperature. The pressure in the reactor increased to $\sim 4-5 \mathrm{MPa}$ upon heating, then continually decreased due to nitrogen dissolution in the melt and consumption by the growth process, $\mathrm{N}_{2}$ reaction with internal reactor components, or $\mathrm{N}_{2}$ leakage. This mode of operation changed the driving force for growth during the run, but in the leakage-free case the total $\mathrm{N}_{2}$ loss was so low that it likely had a negligible effect on the growth process. Process conditions were held for dwell times between 10 and 100 hours before cooldown and de-pressurization of the reactor. A summary of the key process parameters for the reported Gen III growth run is included in Table 1, below.

\begin{tabular}{|c|c|c|c|c|}
\hline Design & $\begin{array}{l}\text { Melt Composition } \\
(\mathrm{mol} \%)\end{array}$ & $\begin{array}{c}\text { Peak } \\
\text { Pressure } \\
\text { (MPa) }\end{array}$ & $\begin{array}{c}\text { Dwell } \\
\text { Temperature } \\
\left({ }^{\circ} \mathrm{C}\right)\end{array}$ & $\begin{array}{l}\text { Dwell } \\
\text { Time } \\
\text { (Hrs) }\end{array}$ \\
\hline Gen III & Ga: 20, Na: 79.5, C: 0.5 & 4.7 & 861 & 103 \\
\hline
\end{tabular}

The actual melt composition must have deviated from the nominal or starting value at some point during the run, but the trajectory was uncertain. As noted above, the high vapor pressure of sodium under growth conditions causes a redistribution of sodium within the accessible volume. We have also observed gallium redistribution under certain conditions as well, but to a much less extent due its much lower vapor pressure. The unequal migrations between sodium and gallium create an "offset" between the actual and nominal melt composition, quite possibly early in the run. Additionally, the melt composition varies throughout the run as the gallium is consumed during growth of solid GaN and sodium evaporates from the melt and condenses on colder surfaces such as the capsule seal plate. Since the melt composition is critical to nitrogen solubility as well as bulk fluid properties, constituent migration processes must be considered from a growth system design and operation standpoint. 
Following the run, the crucible or capsule was removed and opened, and the contents were soaked in a series of isopropanol/water mixtures with increasing water content to slowly and controllably neutralize the sodium. For the carbon-added growth runs, we determined that hydrogen cyanide $(\mathrm{HCN})$ was formed during the neutralization process, based on monitoring of the atmosphere directly above the neutralization beaker using a toxic gas sensor.[18] This was likely due to reaction of residual sodium cyanide $(\mathrm{NaCN})$ with water. If there was any concern over high levels of residual dissolved cyanide in the waste, bleach was added to convert the cyanide to much less volatile and toxic sodium cyanate $(\mathrm{NaOCN})$. If significant amounts of gallium were still present following neutralization, the grown crystals were etched in 3:1 mixture of $\mathrm{HCl}: \mathrm{HNO}_{3}$ (aqua regia) to remove any residual gallium, leaving only crystalline $\mathrm{GaN}$.

Crystals were characterized using powder X-ray diffraction (XRD, X'Pert MPD), secondary electron microscopy (SEM) and cathodoluminescence (CL). For runs exhibiting significant seeded crystal growth, the grown material was characterized by X-ray omega rocking curve ( $\omega$-XRC, Panalytical MPD Pro) measurements about the GaN(0002) reflection as well as secondary ion mass spectroscopy (SIMS, Cameca IMS 7F) along the [0001] growth direction. The $\omega$-XRC measurements were obtained using $\mathrm{CuK \alpha _{1 }}$ radiation with a $10 \mathrm{~mm} \times 1 \mathrm{~mm}$ spot size. For the SIMS analysis, relative sensitivity factors (RSFs) previously calculated at UCSB were used to determine impurity concentrations for oxygen, carbon, sodium, aluminum and chromium. RSF values for sulfur were estimated using literature tables compiled for GaAs,[19] as these values were not known for GaN. Comparison of estimated RSF values to measured values in the case of oxygen and carbon indicated potential underestimation error for this method of up to an order of magnitude.

\subsection{Capsule Materials Corrosion Study}

To identify a metal capable of containing the sodium gallium melt under process conditions, a total of six metals were investigated in the corrosion study. The metals were: SS316, Grade 2 titanium (99.2\% pure), Grade 5 titanium, also known as $6 \mathrm{Al} 4 \mathrm{~V}$ (6 wt \% Al, $4 \mathrm{wt} \% \mathrm{~V}$, balance Ti), TZM, commercially pure nickel, or $\mathrm{Ni} 200$ ( $>99 \%$ nickel) and an iron-cobalt alloy, HiperCo50A ( $49 \mathrm{wt} \% \mathrm{Fe}$, $49 \mathrm{wt} \% \mathrm{Co}, 2 \mathrm{wt} \% \mathrm{~V})$. From an earlier, smaller scale corrosion study, we observed that nickelchromium alloys such as Inconel 625 and Chromel $C$ were likely to rapidly corrode in the melt, and were not tested. However, others have reported some stability of Inconel materials under sodium flux growth conditions.[20, 21] Closed-ended cylinders or thimbles of $19 \mathrm{~mm}$ OD x $16 \mathrm{~mm}$ ID x 10 $\mathrm{mm}$ tall were fabricated from each of the six candidate metals for testing.

The experimental procedure for the corrosion study runs was similar to that detailed above, with the exception that instead of a seed, a corrosion thimble filled with $\sim 5 \mathrm{~g}$ of gallium and $\sim 4 \mathrm{~g}$ of sodium was placed within the alumina crucible, as shown in Figure 2. This gave a melt composition of $27 \mathrm{~mol} \%$ gallium and $73 \mathrm{~mol} \%$ sodium, typical for growth conditions. 


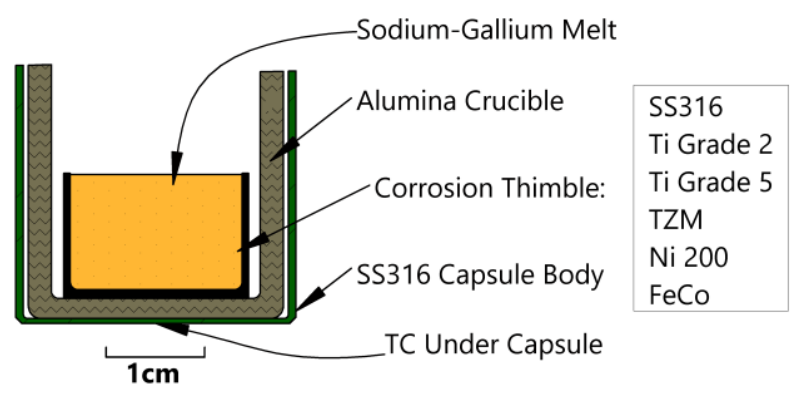

Figure 2. Cross-section view of corrosion study experimental setup.

Each respective corrosion run lasted for 50 hours at a $\mathrm{N}_{2}$ pressure of $\sim 4.5 \mathrm{MPa}$ and $860{ }^{\circ} \mathrm{C}$. After the run, the capsule was neutralized in same manner as above, followed by recovery of the corrosion thimble. The thimbles were analyzed post-run in terms of mass gain or loss, discoloration and obvious interaction with the melt.

\section{Results and Discussion}

\subsection{Gen I: Sodium Loss and PolyGaN Growth}

For initial growth attempts, an alumina crucible loaded with sodium and gallium was placed within a closed-ended and tight-fitting boron nitride receiver covering the entire length of the crucible as shown in Figure 3. Even though the gap between the two components was quite small $(<0.1 \mathrm{~mm})$, it was insufficient to prevent major sodium migration out of the crucible. All of the runs conducted in this manner resulted in large amounts of sodium leakage and in many cases the sodium damaged the hot zone ceramics. The melt temperature for these runs was controlled by a thermocouple placed directly underneath the crucible, as there was no practical access to the melt itself.

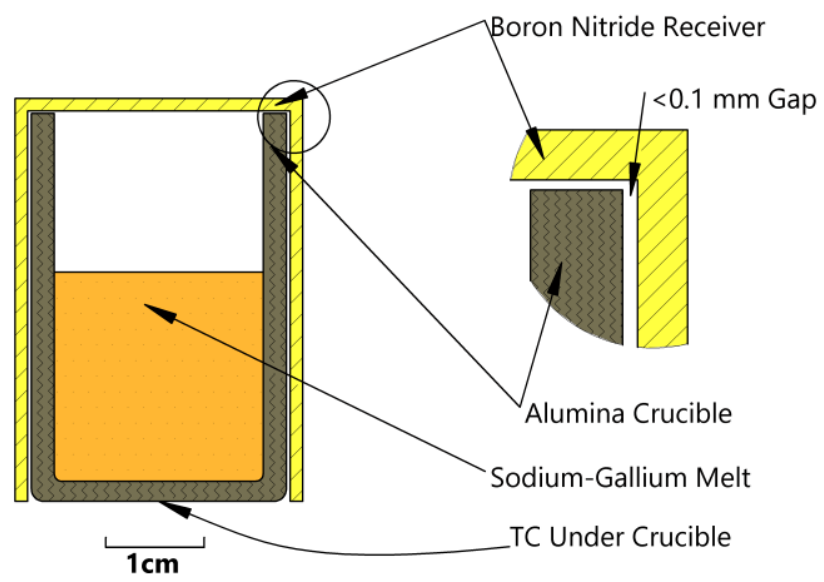

Figure 3. Cross-section view of Gen I crucible-in-receiver design. Inset shows small gap between receiver and crucible. 
Though the early runs demonstrated shortcomings in the sodium containment approach, small (less than $2 \mathrm{~mm}$ in size) black or grey GaN crystallites (PolyGaN) were generally evident either near the melt surface, on the crucible bottom and sidewalls, or both. This indicated that the sodium was present for long enough to provide appreciable nitrogen solubility in the melt. SEM inspection, CL and powder XRD characterization of PolyGaN crystallites nucleated on the crucible sidewall all confirmed the formation of wurtzite GaN produced by our new apparatus.

\subsection{Gen II: Reflux Condenser and First Seeded Growth}

To better control the sodium vapor while allowing $\mathrm{N}_{2}$ gas to remain in contact with the melt we developed a reflux condenser system, which are widely used in organic synthesis and distillation and have been used for bulk crystal growth.[22-24] In this scheme, a sealed sodium-containing capsule was in communication with the reactor interior, but only through a tube which passed through a steep temperature gradient in the ceramic insulation. The sodium freely evaporated from the surface of the melt, but condensed quickly as it traveled upwards and equilibrated with the progressively colder tube or stem. Since temperatures were everywhere above the sodium melting point of $98^{\circ} \mathrm{C}$, the liquid sodium flowed back down the inside wall of the stem and into the melt due to gravity. This mechanism and equipment eliminated gross sodium loss from the melt. And even though the impact on melt composition of the sodium resident in the reflux condenser at any given time (the so-called sodium "offset") was unknown, it should have been consistent run-to-run.

The use of a reflux condenser is a departure from previous reports on using the sodium flux method to produce bulk GaN. We think it offers a number of unique benefits in terms of process control and monitoring. For instance, the results detailed here are, to our knowledge, the first report of controlling the sodium flux crystal growth of GaN using a thermocouple submerged in the melt.

For the Gen II design, we developed a multi-part SS316 capsule system, as shown in Figure 4. The capsule consisted of a lower body or can and an upper body which included a seal plate and the reflux condensing stem. To reduce contamination from the stainless steel and prevent corrosion of the metal during the run, an alumina crucible was used within the capsule lower body to contain the

melt and seeds. A thermocouple inserted within either an alumina or pure molybdenum closed-end tube thermowell was employed for melt temperature control starting with Gen II designs. 


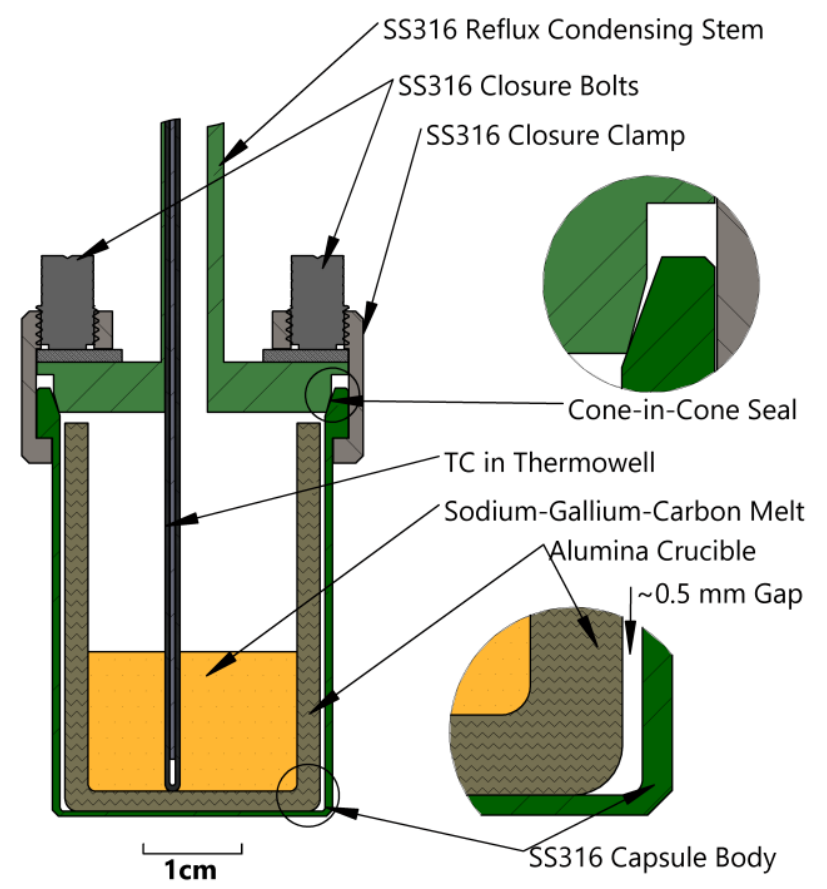

Figure 4. Cross-section view of Gen II SS316 capsule + alumina crucible design. Upper inset shows cone-in-cone seal. Lower inset shows sodium-trapping gap between crucible and inside of capsule.

The Gen II design resulted in successful sodium containment for the entire 100 hour duration of a typical run, and several growth runs were performed using the Gen II configuration. Both GaNon-Sapphire templates as well as HVPE bulk GaN wafers were used as seeds. Other unseeded runs were also performed, which generally resulted in PolyGaN formation. All grown crystals were black, consistent with sodium flux growth without the use of additives such as calcium or lithium.[25] The crystals often had rather rough surface morphologies. Due to the rough surfaces, observed growth rates varied from $2 \mu \mathrm{m} / \mathrm{hr}$ up to $14 \mu \mathrm{m} / \mathrm{hr}$.

SIMS on the Gen II sample was performed along to the growth direction and approaching through the MOCVD GaN seed layer with results shown in Figure 5. The transition between the $\sim 2$ $\mu \mathrm{m}$ thick seed MOCVD GaN seed layer and the grown material is apparent in Figure 5, with high concentrations $\left(>10^{20}\right.$ atoms $\left./ \mathrm{cm}^{3}\right)$ of oxygen, sodium and aluminum present at the regrowth interface. Oxygen impurity concentrations decreased slightly into the grown material, but remained in excess of $10^{19}$ atoms $/ \mathrm{cm}^{3}$. For comparison, both oxygen and sodium levels measured by SIMS reported by the Osaka University group are typically $10^{17}$ atoms $/ \mathrm{cm}^{3}$ or less.[8, 26] Assuming the segregation coefficients were similar in the present case, two possibilities for the increase are: 1) the melt itself had a much higher concentration of one or more of these elements, or 2) poor growth led to trapping of impurities, which did not occur in literature reports. Taking the former scenario, the high oxygen concentration could be due to an overall increase in oxygen contamination from the handling and loading steps in our case. But the latter scenario cannot be ruled out.

Aluminum concentrations were $\sim 10^{20}$ atoms $/ \mathrm{cm}^{3}$ in the sodium flux grown material while chromium was at $\sim 10^{17}$ atoms $/ \mathrm{cm}^{3}$. Both of these were greater than the respective values in the MOCVD GaN seed by roughly two orders of magnitude. Since these elements (sodium, aluminum 
and chromium) all have high oxygen affinities, enrichment in the sodium flux material could have been incidental to the main oxygen contamination or vice versa. Aluminum likely came from the alumina crucible while chromium probably leached from the stainless steel capsule.[21,27] Previous investigations of chromium in the sodium flux process indicated rather low incorporation in $\mathrm{GaN}$ due to preferential formation of $\mathrm{CrN},[28]$ but the concentration in the melt in our present case may have been much greater. Carbon is not shown in Figure 5 since the level hardly changed at the growth interface. The concentration in the sodium flux grown material was $\sim 10^{17}$ atoms $/ \mathrm{cm}^{3}$, similar to literature values.[9]

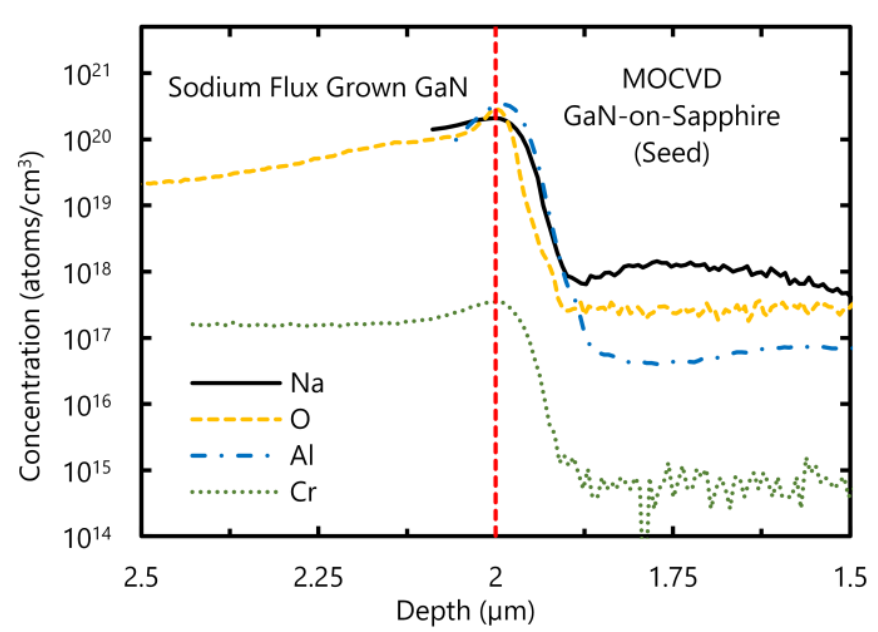

Figure 5. SIMS results for selected elements from the crystal grown in the Gen II crucible + capsule system. Dotted line denotes interface between sodium flux grown GaN and GaN-on-sapphire seed layer of known thickness.

Though the Gen II capsule and crucible system was functional in that it allowed GaN growth while containing the sodium vapor within the capsule, several issues prompted further design improvements. First, the SIMS data indicated that oxygen was a major contaminant, with the alumina crucible a likely oxygen source. Other possible oxygen sources could have been gas desorbed from the high surface area alumina hot zone ceramics or particles shed from the alumina ceramics during reactor loading.

Second, we observed that the annular space between the crucible and the capsule (inset in Figure 4) was consistently full of sodium following the run, even for very fast cooldown times. A change in the melt height during the run was also evident from rings of PolyGaN formed at different heights on the inside of the crucible. Based on this, we concluded that the gap acted as a trap for pure sodium during the run, and the inconsistent position of the PolyGaN melt height rings indicated different amounts of sodium left the melt each run. For our modest system size, the amount of sodium resident in even a small $(0.5 \mathrm{~mm}$ or less) annular gap represented a significant fraction of the overall melt volume, and this uncontrolled sodium loss from the melt likely affected the melt composition and crystal growth process.

Finally, the cone-in-cone capsule seal was in many cases incredibly difficult to release, to the point of requiring the capsule to be sawed open. Strong mechanical bonds have been reported 
between joined stainless steel components exposed to sodium for extended periods above $600{ }^{\circ} \mathrm{C} .[29$, 30] The identified mechanism of "self-welding" was due to formation of sodium chromite $\left(\mathrm{NaCrO}_{2}\right)$ by reaction of sodium with the native chromium oxide on stainless steel, and it is likely the same process occurred in our system. In fact, the observed lack of sodium migration for the Gen II system may have been a consequence of "self-welding" in situ by sodium chromite formation and resulting development of a hermetic capsule seal. Even if the capsule didn't have to be sawed open, the seal area needed to be refinished after every growth run to remove the rough surface produced during de-mounting. Since reusability was a key goal for economic and scale-up reasons, this was a clear drawback of using stainless steel.

\subsection{Capsule Material Corrosion Study}

Given these challenges with a stainless steel-based Gen II design, we put significant effort towards development of a crucible-free and reusable sodium containment system for the Gen III system. To be crucible-free the capsule had to be made from a material able to withstand corrosion from sodium, gallium and nitrogen at the growth conditions for long periods. Additionally, the material must be somewhat malleable and readily fabricable to form the required hermetic seal and reflux condenser. Based on a literature review and practical considerations, a few candidate materials were evaluated as part of a corrosion study.

As detailed above, the six materials tested in the corrosion study were SS316, two grades of titanium (Ti Grade 2, Ti Grade 5), pure nickel (Ni 200), TZM and an iron-cobalt alloy (HiperCo50A). All corrosion thimbles survived the 50 hour run at $860^{\circ} \mathrm{C}$ without major dissolution or etching. In fact, post-run measurement showed that all the samples gained mass, and gallium appeared to be the major interacting element. This was not surprising, given that at least one intermetallic phase is present in the binary system with gallium for all major metal constituents tested.[31] In some cases, the interaction was obvious: the Ni 200 sample came out with a uniform shell or coating of gallium, the titanium samples were mostly covered with gallium post-run, and the SS316 sample showed evidence of gallium diffusion through the $\sim 1.5 \mathrm{~mm}$ thick wall. Though gallium appeared to be the major interacting element, there was evidence of other interactions as well. For instance, uncovered titanium surfaces were colored gold, indicative of TiN formation.

To account for density differences between samples, we assessed the mass gain as compared to the initial mass of gallium for each respective run, as shown in Figure 6. Error from lumping other interactions (e.g., nitridation) into this metric was likely small due to the observable extent of the gallium interaction as well as the large density difference between nitrogen or sodium with respect to gallium. 


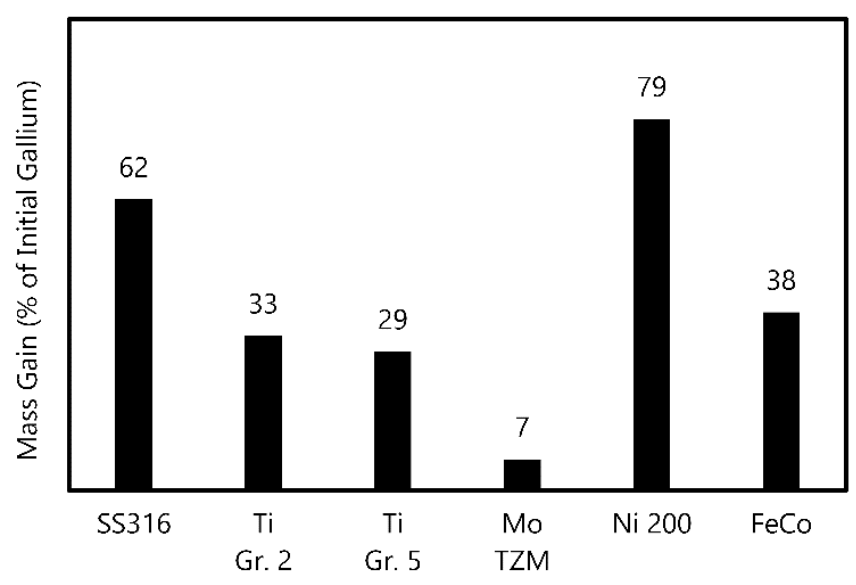

Figure 6. Corrosion study results shown as post-run weight gain as a percentage of initial gallium mass. This value also includes mass gain from sources other than gallium uptake, such as nitridation or reaction with sodium.

Of all the samples tested, TZM had the least amount of mass gain, and showed no major signs of mechanical or chemical degradation. Therefore, TZM was selected for further capsule design development. The choice between testing pure molybdenum or TZM was due solely to availability of materials, but the earlier corrosion study and experience with pure molybdenum thermowells indicated that pure molybdenum would also likely perform well. It should be noted that since no major degradation or corrosion took place for any of the materials tested, it is possible they could be used for capsule fabrication or capsule cladding, albeit with some increased expected interaction with gallium as compared to TZM.

Spontaneously nucleated PolyGaN formation was evident for some samples at the meltsurface between the corrosion thimble and the crucible. This was important from a design standpoint because it confirmed there was no poisoning or growth inhibition effect due to any of the tested materials. The PolyGaN was typically dark brown or black, except in the case of the Mo TZM capsule, where it appeared grey. No characterization of the PolyGaN from these runs was performed.

\subsection{Gen III: Molybdenum-Based Capsule}

For the Gen III design, we introduced TZM components while retaining the proven successful reflux condenser feature and thermocouple-in-thermowell configuration for temperature control. Though the TZM-based Gen III system was nominally a crucible-free design, there is nothing about this approach that precludes the use of a crucible as well since the major dimensions weren't modified from the Gen II design. The initial Gen III design used a similar cone-in-cone seal as in previous capsules made from stainless steel. To maintain close matching of thermal expansion throughout the assembly, the clamp also needed to be made from TZM. In this case the sealing force between the lower can and the upper seal plate was applied by one large nut acting on a thrust washer, as the TZM cracked and failed when subjected to large moments produced by the bolt ring configuration used in the Gen II design.

ReSubmit_IWBNS IX System Paper Manuscript_PVD_v27 
It proved difficult to realize a hermetic seal even under ambient conditions with the TZM cone-in-cone seal, likely due to the poor surface finish produced from machining TZM and the difficulties in polishing this material.[32,33] To overcome this, we introduced a knife-edge seal with a gasket, as shown in Figure 7.

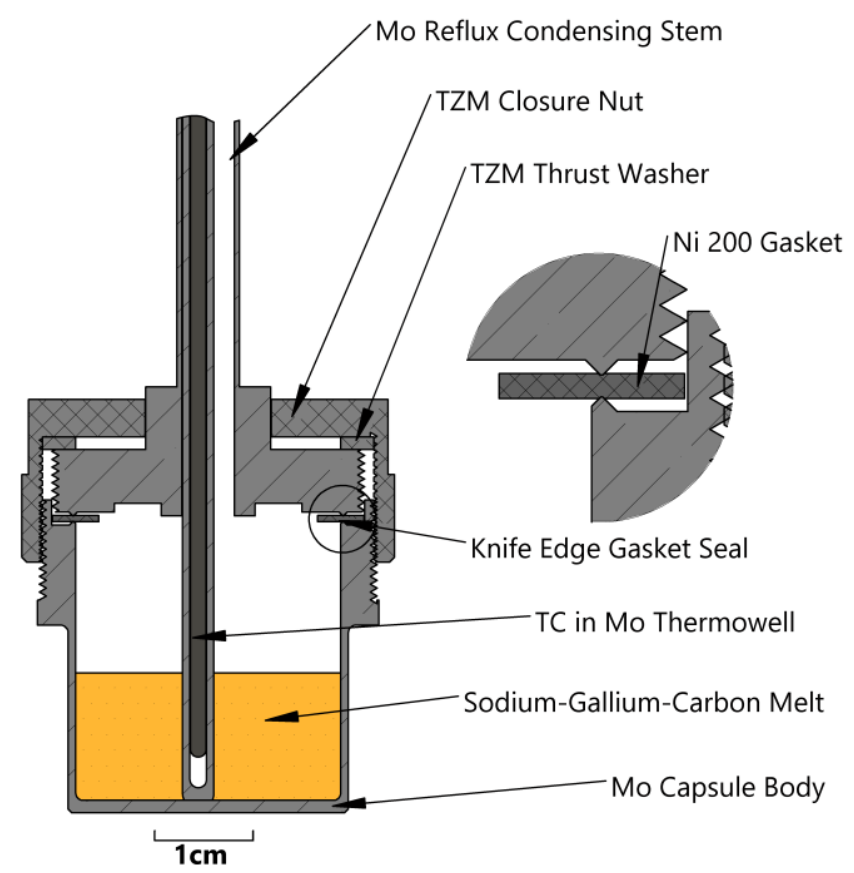

Figure 7. Cross-section view of Gen III crucible-free capsule. Inset shows knife-edge gasket seal.

After trying several gasket materials, thicknesses and finishes, $635 \mu \mathrm{m}$ thick highly polished pure nickel was found to show acceptable performance, with no evidence of sodium leakage. In fact, post-thermal cycle observations revealed that a strong bond was formed between the nickel and molybdenum or TZM. Migration of molybdenum into the nickel gasket was confirmed using energy dispersive X-ray spectroscopy (EDX), with molybdenum concentrations $>25$ at $\%$ as deep as $\sim 40 \mathrm{um}$ into the gasket. Strong interaction and adhesion between nickel and knife edges is consistent with the presence of several Ni-Mo intermetallic compounds[34] as well as reports of facile diffusion bonding.[35, 36]

Since TZM has a much higher thermal conductivity than SS316,[37, 38] there was some risk that the thermal gradient up the reflux condenser would be insufficient to prevent sodium escape into the remainder of the reactor. To compare the two cases quantitatively, a Gen III capsule was fabricated from an SS316 upper seal plate with an Inconel 718 nut and lower body. Multiple thermocouples were inserted at varying heights within the thermowell for both the TZM and SS316/Inconel 718 capsules and the capsules were thermal cycled to $860^{\circ} \mathrm{C}$ in separate runs. The steady-state vertical temperatures are compared in Figure 8, below. 


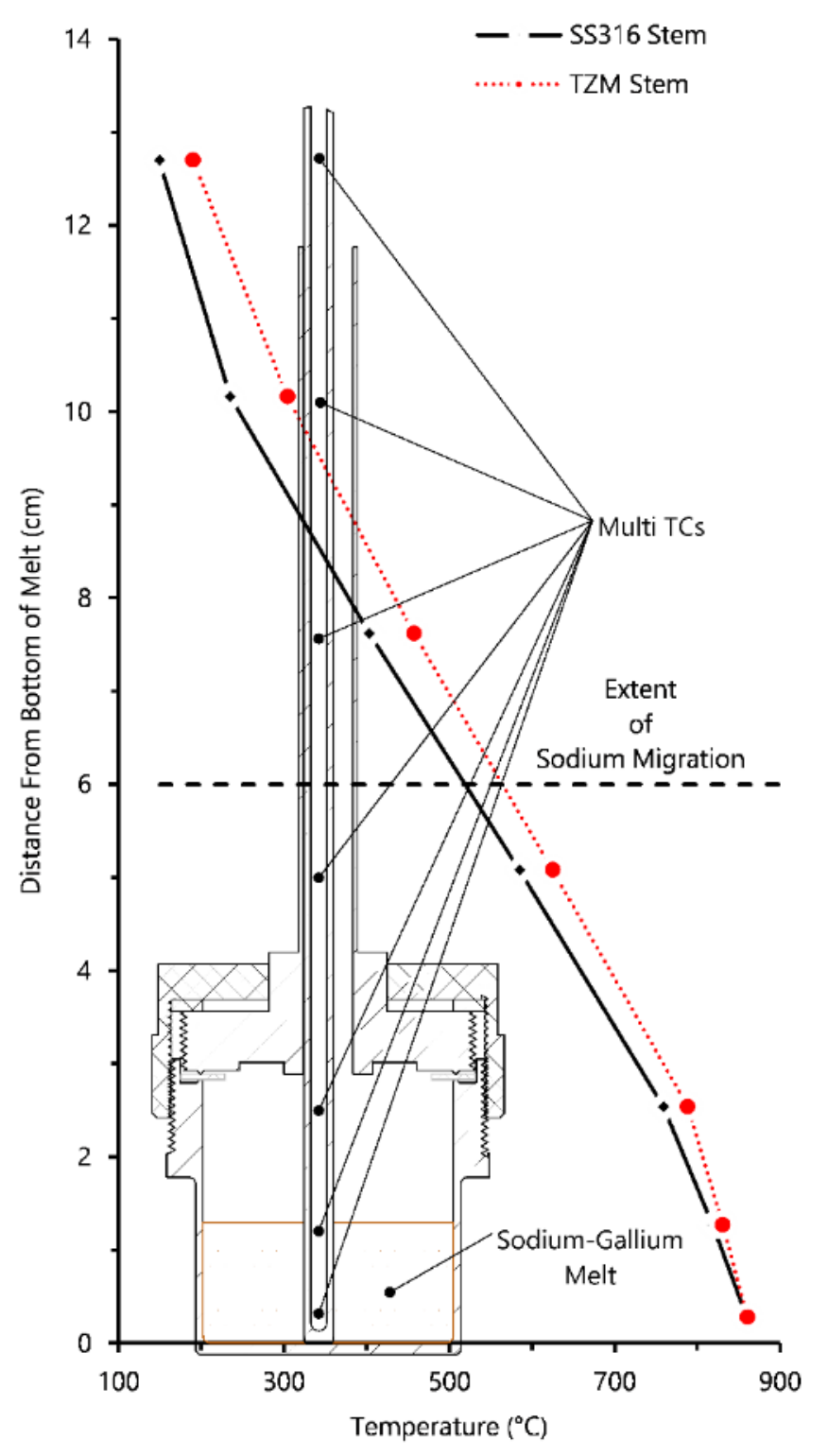

Figure 8. Temperatures ascending the reflux condenser stem for both SS316 and TZM Gen III capsules. Sodium was typically found after the run up to $\sim 6 \mathrm{~cm}$ above the bottom of the melt, as shown by dotted line.

There was some modest increase in temperatures at all points up the stem for the TZM capsule, as expected for the much larger thermal conductivity. The largest difference between the two occurred at $\sim 10 \mathrm{~cm}$ above the bottom of the melt, where the TZM capsule was $\sim 70{ }^{\circ} \mathrm{C}$ hotter than the SS316/Inconel 718 capsule. More importantly, post-run inspection showed no indication of sodium escape for either stem material, and the typical extent of sodium migration was $\sim 3 \mathrm{~cm}$ above the bottom of the seal plate, or $\sim 6 \mathrm{~cm}$ from the bottom of the melt, indicating that the sodium vapor pressure was appreciably low at the top of the stem in both cases.

These studies also revealed the possibility of a large temperature gradient within the melt itself, with the temperature dropping by as much as $40^{\circ} \mathrm{C}$ over a typical melt height of $\sim 1.5 \mathrm{~cm}$. More 
detailed measurements and modeling need to be done to determine if the melt actually exhibits such a strong vertical gradient, or if the thermal standoff between the thermocouple and the inside of the thermowell can explain the values. It seems unlikely that a high conductivity melt such as sodiumgallium could possibly support such a strong gradient in any case. But if so, this gradient likely has large implications for the crystal growth process.[39]

Post-run measurements showed a significant increase in the nickel gasket thickness of the area where the gasket was exposed to the process environment inside the seal line for certain runs with the gasket-sealed Gen III system. In one case, the thickness increase was as much as $20 \%$ along with a $14 \%$ increase in the gasket mass. Further investigation using EDX on cross-sectioned post-run gasket revealed gallium up to $\sim 200 \mu \mathrm{m}$ deep, with concentrations as high as $50 \mathrm{wt} \%$. No measurable amounts of nitrogen or sodium were detected. Assuming the entire gasket mass gain was gallium, the melt lost $\sim 8 \%$ of the initial charge. In other cases, the mass gain of the gasket represented $<1 \%$ of the initial charge. The exact mechanism for gallium migration under these conditions is not clear, but it is not surprising that the nickel gasket readily absorbed gallium due to the several stable Ni-Ga intermetallic phases,[40] as well as the results of the corrosion study. Further study into the migration of the gallium could yield insight into the growth process, as preliminary observations indicate some rough correlation between amount of gallium absorbed and amount of grown GaN.

The Gen III all-TZM capsule was used with a $\sim 1 \mathrm{~cm}$ square $c$-plane HVPE GaN seed mounted vertically within the melt. For this run, carbon was added for PolyGaN suppression. GaN was successfully grown on both the (0001) Ga and (0001) N faces in roughly equal amounts $(\sim 60 \mu \mathrm{m}$ each side, $\sim 120 \mu \mathrm{m}$ total) for this run, yielding a growth rate of $\sim 0.5 \mu \mathrm{m} / \mathrm{hr}$. This growth rate is much lower than reported values of $\sim 30 \mu \mathrm{m} / \mathrm{hr}$ for similar growth conditions.[41] Once again, the grown material was quite black, but had a smooth surface appearance. A small change in thickness of the grown crystal was evident along the vertical direction, with the top $15 \mu \mathrm{m}$ thicker than the bottom

The tapered growth profile is more consistent with growth controlled by nitrogen concentration in the melt, which must decrease away from the free melt surface.[39] The growth rate may have been low compared to literature values due to the absence of stirring or any sort of mixing of the melt.[42] But this view is inconsistent with a steep vertical temperature gradient in the melt, which would give rise to strong melt convection as well as large changes in nitrogen solubility over the crystal face. 

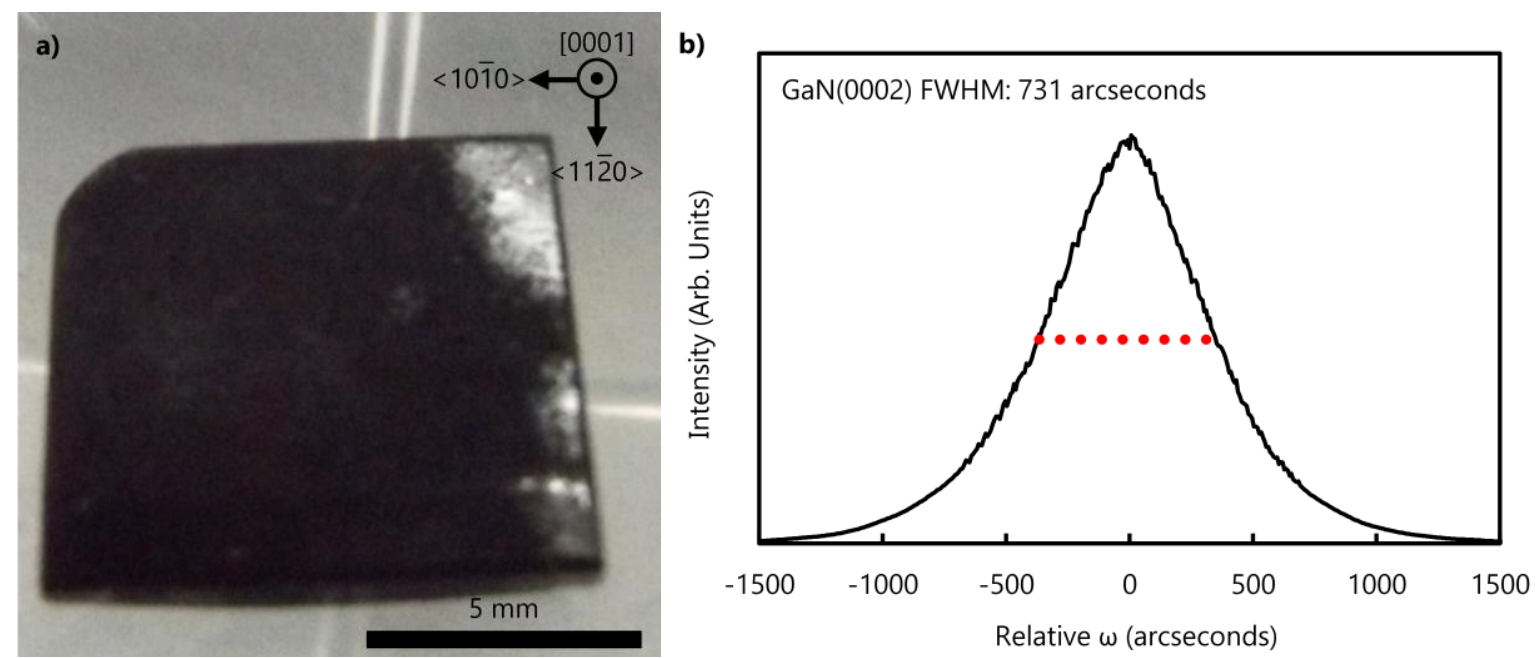

Figure 9. a) Crystal grown from $1 \mathrm{~cm} x 1 \mathrm{~cm}$ HVPE seed in Gen III crucible-free TZM capsule system. b) $\omega$-XRC from (0001) Ga face of crystal shown in a) showing single peak and a FWHM of 731 arcseconds.

Both the (0001) Ga and (0001) N face $\mathrm{GaN}(0002) \omega$-XRC results showed a clear single peak, with on-axis full-width at half maximum (FWHM) values of 735 and 731 arcseconds, respectively. The (0001) Ga face results are shown in Figure 9b. While the presence of a single peak indicates growth of single crystal GaN, the FWHM values were still in excess of literature values for large-area growth. Additionally, FWHM values for the as-received HVPE seeds were typically in the range of 20-50 arcseconds. Thus, the crystal growth did not replicate the seed quality, likely due to poor nucleation. One reason nucleation control is difficult in the sodium flux method is the presumed early-stage etch-back or dissolution of the seed into the melt prior to saturation with nitrogen.[43] It is likely careful attention will need to be given to the growth initiation to realize high quality GaN using the sodium flux method. For example, the Osaka University group has utilized the point-seed technique to better control the nucleation process,[11] with reported $\mathrm{GaN}(0002) \omega$-XRC FWHMs as low as 28 arcseconds.[44]

Figure 10 compares concentrations of major impurities measured using SIMS for crystals grown using the Gen III and Gen II systems, respectively. Values for the Gen II system were taken from data previously shown in Figure 5 while values for the Gen III system were obtained from a SIMS depth profile of the as-grown (0001) Ga face of the crystal shown in Figure 9a.

The Gen III crystal oxygen concentration increased with respect to the Gen II results by about an order of magnitude, to $\sim 10^{20}$ atoms $/ \mathrm{cm}^{3}$. Sodium and carbon remained at $>10^{19}$ and $\sim 10^{17}$ atoms $/ \mathrm{cm}^{3}$, respectively, for the Gen III system with the sodium still much greater than literature reports.[8] 


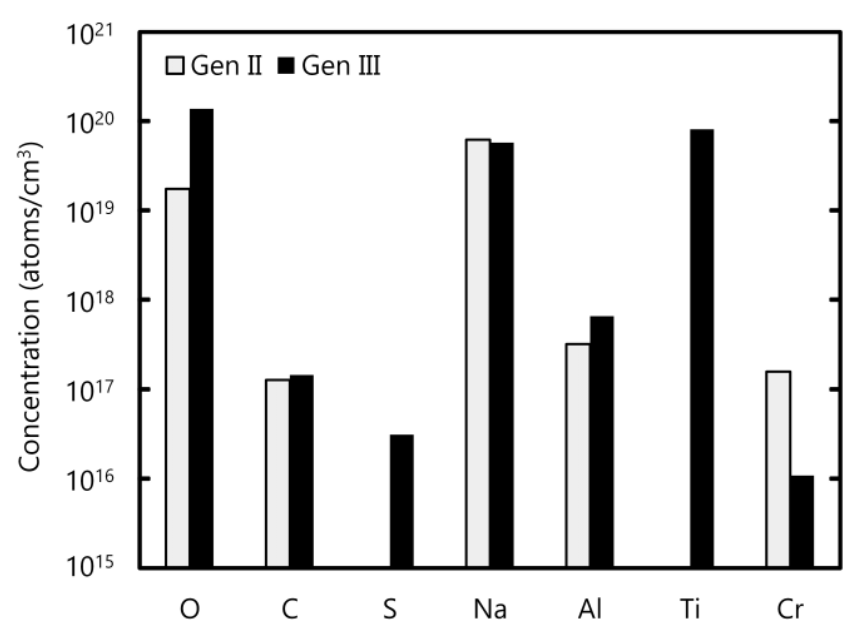

Figure 10. Comparison of SIMS results for selected elements in GaN crystals grown in Gen II (alumina crucible in SS316 capsule) and Gen III (crucible-free Mo/TZM capsule) systems, respectively.

Sulfur was present at low levels $\sim 10^{16}$ atoms $/ \mathrm{cm}^{3}$, and was likely introduced through the use of $\mathrm{MoS}_{2}$ dry lubricant on the Gen III capsule sealing nut. Sulfur could be reduced through a capsule redesign and/or better handling procedures, though it is not clear how deleterious sulfur might be to the optoelectronic properties of GaN.[45] It was surprising that the aluminum content increased in the Gen III case, since the alumina crucible used for the Gen II design was eliminated. It is possible the alumina hot zone ceramics were the major aluminum (and oxygen) source, as they tended to easily shed dust and particles during reactor handling and loading. The estimated titanium concentration was $\sim 10^{19}$ atoms $/ \mathrm{cm}^{3}$, and likely leached from the TZM capsule. This could be addressed by utilizing pure molybdenum in lieu of TZM in future designs. Chromium was reduced by an order of magnitude in the Gen III system compared to the Gen II design, as expected for a shift away from a stainless steel capsule.

As was the case for the Gen II results, it is difficult to conclude if the high oxygen levels led to high concentrations of metals such as sodium, titanium and aluminum, or if the opposite occurred. Additionally, it is not clear if the overall elevated impurity levels for our system with respect to literature reports are due to some fundamental flaw in system design, raw materials, etc., or if they were more a product of our still unrefined reactor loading and handling procedures.

\section{Conclusions}

After three major design generations and numerous growth runs, we successfully demonstrated the implementation of a crucible-free system for $\mathrm{GaN}$ growth using the sodium flux method. The use of a reflux condensing stem for sodium containment has proven to be a robust and readily implemented solution. Furthermore, it opened the possibility of temperature control through a thermocouple adjacent to the seed crystal, a first for the sodium flux method. Of several metals tested for corrosion compatibility with the sodium-gallium melt, molybdenum-based TZM alloy 
showed the most encouraging results in terms of low interaction with gallium or sodium under growth conditions.

Introduction of TZM into the capsule design enabled crucible-free growth of single crystal $\mathrm{GaN}$ from a bulk GaN seed. Growth rates were lower than literature values, while $\omega$-XRC FWHMs and impurity levels were significantly higher. The handling procedures, growth initiation and overall growth conditions have not been optimized for our new system, so it is likely improvements can be made in all these areas.

\section{Acknowledgements}

Thanks to Guy Patterson and Doug Rehn for help with many aspects of equipment design and fabrication. Thanks to Dr. Tom Mates for performing the SIMS measurements and to Steven Griffiths and Thomas Malkowski for many helpful conversations and insights. The authors acknowledge the support from the Solid State Lighting and Display/Energy Center at, University of California, Santa Barbara and the Materials Research Laboratory (MRL) Central Facilities, which are supported by the MRSEC Program of the NSF under Award no. DMR 1121053; a member of the NSF-funded Materials Research Facilities Network (www.mrfn.org). This work was supported by the KACST-KAUSTUCSB Solid State Lighting Program.

\section{References}

1. Mishra, U.K., et al., GaN-Based RF Power Devices and Amplifiers. Proceedings of the IEEE, 96(2): p. 287-305. (2008)

2. Utsumi, W., et al., Congruent Melting of Gallium Nitride at 6 GPa and Its Application to SingleCrystal Growth. Nature Materials, 2(11): p. 735-738. (2003)

3. Porowski, S., et al., The Challenge of Decomposition and Melting of Gallium Nitride under High Pressure and High Temperature. Journal of Physics and Chemistry of Solids, 85: p. 138-143. (2015)

4. Fujito, K., et al., Bulk GaN Crystals Grown by HVPE. Journal of Crystal Growth, 311(10): p. 30113014. (2009)

5. Pimputkar, S., et al., Improved Growth Rates and Purity of Basic Ammonothermal GaN. Journal of Crystal Growth, 403: p. 7-17. (2014)

6. Yamane, H., et al., Preparation of GaN Single Crystals Using a Na Flux. Chemistry of Materials, 9(2): p. 413-416. (1997)

7. Mori, Y., et al., Growth of Bulk GaN Crystal by Na Flux Method under Various Conditions. Journal of Crystal Growth, 350(1): p. 72-74. (2012)

8. Mori, Y., et al., Growth of GaN Crystals by Na Flux Method. ECS Journal of Solid State Science and Technology, 2(8): p. N3068-N3071. (2013)

9. Kawamura, F., et al., Effect of Carbon Additive on Increases in the Growth Rate of 2 in GaN Single Crystals in the Na Flux Method. Journal of Crystal Growth, 310(17): p. 3946-3949. (2008) 
10. Kawamura, T., et al., Structural Analysis of Carbon-Added Na-Ga Melts in Na Flux GaN Growth by First-Principles Calculation. Japanese Journal of Applied Physics, 52(8S): p. 08JA04. (2013)

11. Imade, M., et al., Centimeter-Sized Bulk GaN Single Crystals Grown by the Na-Flux Method with a Necking Technique. Crystal Growth \& Design, 12(7): p. 3799-3805. (2012)

12. Savage, H., et al., Snap-8 Corrosion Program Summary Report. (ORNL-3898): p. 1-207. (1965)

13. Shin, S.H., S.H. Kim, and J.H. Kim, Model of Liquid Gallium Corrosion with Austenitic Stainless Steel at a High Temperature. Journal of Nuclear Materials, 450(1): p. 314-321. (2014)

14. Von Dollen, P., et al., A New System for Sodium Flux Growth of Bulk GaN Part II: in situ Growth Processes. Journal of Crystal Growth. (submitted)

15. Seidl, A., et al., 200mm GaAs Crystal Growth by the Temperature Gradient Controlled LEC Method. Journal of Crystal Growth, 225(2): p. 561-565. (2001)

16. Yaws, C.L., P.K. Narasimhan, and C. Gabbula, Yaws' Handbook of Antoine Coefficients for Vapor Pressure Knovel (Internet) ed.: Knovel. ISBN: 1591248795 (2005)

17. Hoshino, H. and H. Endo, Pressure Effect on the Concentration Fluctuations for Liquid Na-Ga and Na-Cd Mixtures with S-Shape Liquidus Curves. Physics and Chemistry of Liquids, 11: p. 327-342. (1982)

18. Kawamura, T., et al., Mechanism for Enhanced Single-Crystal GaN Growth in the C-Assisted NaFlux Method. Applied Physics Express, 9(1): p. 015601. (2016)

19. Wilson, R.G., SIMS Quantification in Si, GaAs, and Diamond-an Update. International Journal of Mass Spectrometry and Ion Processes, 143: p. 43-49. (1995)

20. de Jong, A.E.F., et al., A Sample Chamber for in Situ High-Energy X-ray Studies of Crystal Growth at Deeply Buried Interfaces in Harsh Environments. Journal of Crystal Growth, 420: p. 84-89. (2015)

21. Park, S., et al., Growth and Impurity Study of GaN Single Crystal Grown by Na Flux. Journal of the Korean Physical Society, 42: p. S161-S164. (2003)

22. Girard, R. and J. Chang, Reflux Condensation Phenomena in Single Vertical Tubes. International Journal of Heat and Mass Transfer, 35(9): p. 2203-2218. (1992)

23. Steininger, J., High Pressure Reflux Technique for Growth of $\mathrm{Hg}(1-x) \mathrm{Cd}(x) \mathrm{Te}$ Crystals. Journal of Crystal Growth, 37(2): p. 107-115. (1977)

24. Nassau, K., Growth of Crystals from Boiling Solution. Journal of Crystal Growth, 15(3): p. $171-173$. (1972)

25. Konishi, Y., et al., Growth of Prismatic GaN Single Crystals with High Transparency on Small GaN Seed Crystals by Ca-Li-Added Na Flux Method. Applied Physics Express, 5: p. 025503. (2012)

26. Kawamura, F., et al., Growth of a Two-Inch GaN Single Crystal Substrate Using the Na Flux Method. Japanese Journal of Applied Physics, 45(43): p. L1136-L1138. (2006)

27. Ganesan, V. and V. Ganesan, Corrosion of Annealed AISI 316 Stainless Steel in Sodium Environment. Journal of Nuclear Materials, 256(1): p. 69-77. (1998)

28. Aoki, M., et al., Influence of 3d-Transition-Metal Additives on Single Crystal Growth of GaN by the Na Flux Method. Japanese Journal of Applied Physics, 42(Part 1, No. 9A): p. 5445-5449. (2003)

29. Barker, M. and D. Wood, The Corrosion of Chromium, Iron, and Stainless Steel in Liquid Sodium. Journal of the Less Common Metals, 35(2): p. 315-323. (1974)

30. Bendorf, K., Experimental Investigations of Self-Welding of Structural Materials under Sodium. Nuclear Engineering and Design, 14(1): p. 83-98. (1970)

ReSubmit_IWBNS IX System Paper Manuscript_PVD_v27 
31. Predel, B., Landolt-Bornstein: Phase Equilibria, Crystallographic and Thermodynamic Data of Binary Alloys, O. Madelung, Editor. Springer-Verlag: Berlin, Heidelberg. ISBN: (1996)

32. Yoder Jr, P.R., Opto-Mechanical Systems Design. Third ed. Boca Raton, Florida: CRC Press/Taylor and Francis. ISBN: 9781420027235 (eBook - PDF) (2005)

33. Bennett, J.M., S.M. Wong, and G. Krauss, Relation between the Optical and Metallurgical Properties of Polished Molybdenum Mirrors. Applied Optics, 19(20): p. 3562-3584. (1980)

34. Okamoto, H., Mo-Ni (Molybdenum-Nickel). Journal of Phase Equilibria, 12(6): p. 703-703. (1991)

35. Kazakov, N., ed. Diffusion Bonding of Materials. Pergamon Press: Oxford. ISBN: 9780080325505 (1985)

36. Bhanumurthy, K. and R. Schmid-Fetzer, Diffusion Bonding of the Mo-Base Alloy TZM with Interlayers. International Journal of Materials Research, 99(7): p. 766-772. (2008)

37. Ho, C.Y., R.W. Powell, and P. Liley, Thermal Conductivity of the Elements. Journal of Physical and Chemical Reference Data, 1(2): p. 279-421. (1972)

38. Kim, C.S., Thermophysical Properties of Stainless Steels. (ANL-75-55): p. 24. (1975)

39. Gejo, R., et al., Effect of Thermal Convection on Liquid Phase Epitaxy of GaN by Na Flux Method. Japanese Journal of Applied Physics, 46(12): p. 7689-7692. (2007)

40. Okamoto, H., Ga-Ni (Gallium-Nickel). Journal of Phase Equilibria and Diffusion, 31(6): p. 575576. (2008)

41. Imade, M., et al., Growth of Large GaN Single Crystals on High-Quality GaN Seed by Carbon-Added Na Flux Method. Appled Physics Express, 3(7): p. 075501. (2010)

42. Murakami, K., et al., Effects of Solution Stirring on the Growth of Bulk GaN Single Crystals by Na Flux Method. Japanese Journal of Applied Physics, 52: p. 08JA03. (2013)

43. Sato, T., et al., Homoepitaxial Growth of GaN Crystals by Na-Flux Dipping Method. Japanese Journal of Applied Physics, 54(10): p. 105501. (2015)

44. Imade, M., et al., Fabrication of Low-Curvature 2 In. GaN Wafers by Na-Flux Coalescence Growth Technique. Applied Physics Express, 7: p. 035503. (2014)

45. Saxler, A.W., et al., GaN Doped with Sulfur. Materials Science Forum, 258-263: p. 1161-1166. (1997) 